\title{
nature
}

Vol 437 | Issue no. 7055 | 1 September 2005

\section{Responding to uncertainty}

\section{Public controversies that involve scientific uncertainty can be influenced by mavericks. Open confrontation and analysis serves the public better than excommunication.}

$$
\text { d }
$$

n May 2002, the Science Media Centre (SMC), a UK organization dedicated to providing journalists with access to scientists, conducted a closed seminar in which government officials, reporters, researchers and others reviewed a calamity of communication and of public response to science. The flashpoint had been some ill-judged remarks made at a press conference in late 2001, suggesting that the triple-vaccine regimen supplied to the UK population against measles, mumps and rubella might be associated with autism. What followed were campaigns by the government to reassure parents, and by parents for separate vaccines on demand and against alleged conspiracies by the scientific establishment. As a result, many children were not vaccinated, and deaths resulted that could have been avoided.

The seminar concluded on a dilemma that still faces any government faced by a crisis bedevilled with scientific uncertainties, such as today's threat of avian flu. Is it better for authorities simply to reassure, resisting discussion of uncertainties in the expectation that the public would be paralysed or panic-stricken by the lack of clarity? Or should leaders assume a degree of maturity on the part of the media and public, and represent the state of the science, risks and all?

Nature would always urge the latter. But the mass media find it hard to handle scientific uncertainty - and all the more so when vocal scientists promote minority views that have their own appeal to segments of the public, and which gain profile because of media obligations to provide balance. All the more onus on other scientists, then, to help journalists with analyses for public consumption.

Learned societies have a particular responsibility in such circumstances. They should not wait to be called on by a government to provide an analysis. Rather, where the stakes for public interests are high, they should promptly convene a working group charged with delivering a statement of the state of relevant evidence, within a few days if necessary. Above all, they should provide the media with succinct statements and readily reproducible graphics that clearly illustrate not only the conclusions drawn by the working group but also the state of the uncertainties. And where there is a maverick voice, that extreme perspective needs to be exhibited as such. It should be presented in the context of the range of scientific judgement: not dismissed by assertion, but discussed and visualized against a background of expert opinion and the conclusions of studies.

Some societies have been known to lobby the media publicly or discreetly to try to discourage them from allowing minority voices to be heard. Nothing could be more counter-productive. Even if a high-profile scientist is judged by peers to be lacking credibility, the media will rightly be provoked by attempts at censorship, which fuel allegations of a conspiracy, adding perceived weight to maverick claims. It is better to attack such claims explicitly on a scientific basis.

Such problems arise in any scientific country. The SMC has made a particular contribution to mitigating them in Britain. The brainchild of Susan Greenfield, the director of the Royal Institution of Great Britain, which hosts it, its success can be credited above all to the robust
"TheUK Science Media Centre provides quotes from experts in immediate response to breaking stories, and in-depth briefings for longerrunning controversies." leadership of its director Fiona Fox. It provides quotes from experts in immediate response to breaking stories, and in-depth briefings for longer-running controversies. It tutors scientists in communicating complexities such as risk with respectable but effective soundbites. In all of this it acts independently, on behalf of both journalists and scientists - but it ultimately serves the media. Other countries are beginning to take note of the SMC, and Australia is set to clone it.

The media cannot always be trusted - sometimes for lack of resources and knowledge, or for rank editorial bias. But whether scientists take initiatives themselves through campaigning and blogging, or learned societies get sharp, or intermediaries such as the SMC are established, journalists and the public need to be treated as the sophisticated recipients of prompt and well tailored information that most of them are.

\section{Still not deterred}

\section{Universities should back researchers determined to stand up for animal research in the face of terrorism.}

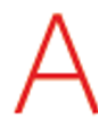
round 18 months ago, under the title "Defeated but not deterred", this magazine published an editorial on animalrights activism in Britain. A campaign of violence and vandalism had just forced the University of Cambridge to cancel plans for a primate research laboratory. Nature suggested then that the victory would not necessarily be repeated. We wish we had been right, but that optimism now looks premature.

The extremists have now secured another success. Darley Oaks is a small family farm in the Midlands. The owners have been breeding guinea pigs for medical research for more than a decade. For the last six of those years, they have suffered a campaign of arson attacks and death threats, and have seen letters of abuse sent to people connected with their business. The campaign culminated in macabre fashion last October, when the remains of a family relative were dug up and removed by protestors demanding that the business close. Last week, the family decided to comply. 